\title{
Consumption behaviour of rural households: A micro level study of Rajasthan, India
}

\author{
PHOOL CHAND MEENA, PREM CHAND MEENA AND LOKESH KUMAR \\ JAIN
}

Article Chronicle :

Received :

25.04.2017;

Accepted :

24.07.2017

KeY Words:

Changing pattern,

Food consumption, Calorie intake, Milk, Meat, Fruits

Author for correspondence : PHOOL CHAND MEENA College of Agriculture, Agriculture University, JODHPUR (RAJASTHAN) INDIA

See end of the article for authors' affiliations

How to cite this article : Meena, Phool Chand, Meena, Prem Chand and Jain, Lokesh Kumar (2017). Consumption behaviour of rural households: A micro level study of Rajasthan, India. Agric. Update, 12(3): 502-508; DOI : 10.15740/HAS/AU/12.3/502-508.

\section{BACKGROUND AND OBJECTIVES}

Changing pattern in food consumption and calorie intake has captured great attention among researchers and policy makers for a long time in India. Increasing preferences towards non-food from food items and from low to high value foods is evident in last three decades. NSS survey reveals that, share of consumption expenditure on food items had declined from 64.0 per cent in 1977-78 to 53.6 per cent in 2009-10 in rural India. In urban India, it was 56.4 per cent and 40.7 per cent, respectively during the periods (NSSO, 2010). Within food items, diversification from cereal dominated low-value traditional food basket towards high value commodities such as milk, meat, fruits, fish, processed food products etc. has been observed in several studies (Radhakrishna, 2006 and Kumar et al., 2006; 2007 and 2011). While the share of cereals in total consumer expenditure in rural India declined steadily from 26.3 per cent in 197778 to 22.2 per cent in $1999-00$ and to 15.6 per cent in 2009-10, expenditure on milk and milk products, egg, fish and meat, fruits and vegetables had increased gradually. Decline in cereal consumption expenditure was also noticed in urban India, although not as severely as was in rural regions. But the income spent on high value commodities remained decreasing, converse to the rural case (NSSO, 2010). While some authors note this decline as an indicator of improvement in welfare (Rao, 2000), others argue that the increasing expenditure on non-food items was not because of welfare improvement but because of increase in prices of essential non-food items like fuel, light, medical expenses, etc. (Saha, 2000).

While the real per capita consumption, income and wages are gradually increasing (in real terms), there has also been an offsetting reduction in calorie consumption. The mean per capita calorie consumption per day in rural India decreased from $2240 \mathrm{Kcal}$ in 1983 to $2047 \mathrm{Kcal}$ in 2004-05. The decline was about 10 per cent, being higher at the upper end of the expenditure distribution. In 